\title{
WELDING THERMAL CYCLE-TRIGGERED PRECIPITATION PROCESSES IN STEEL S700MC SUBJECTED TO THE THERMO-MECHANICAL CONTROL PROCESSING
}

\begin{abstract}
This study presents tests concerned with welding thermal process-induced precipitation processes taking place in $10 \mathrm{~mm}$ thick steel S700MC subjected to the Thermo-Mechanical Control Process (TMCP) with accelerated cooling. The thermomechanical processing of steel S700MC leads to its refinement, structural defects and solutioning with hardening constituents. Tests of thin foils performed using a transmission electron microscope revealed that the hardening of steel S700MC was primarily caused by dispersive $(\mathrm{Ti}, \mathrm{Nb})(\mathrm{C}, \mathrm{N})$ precipitates (being between several and less than twenty nanometers in size). In arc welding, depending on a welding method and linear energy, an increase in the base material in the weld is accompanied by the increased concentration of hardening microagents in the weld. The longer the time when the base material remains in the liquid state, the greater the amount of microagents dissolved in the matrix. During cooling, such microagents can precipitate again or remain in the solution. An increase in welding linear energy is accompanied by an increase in the content of hardening phases dissolved in the matrix and, during cooling, by their another uncontrolled precipitation in the form of numerous fine-dispersive $(\mathrm{Ti}, \mathrm{Nb})(\mathrm{C}, \mathrm{N})$ precipitates of several $\mathrm{nm}$ in size, leading to a dislocation density increase triggered by type 2 internal stresses.
\end{abstract}

Keywords: precipitation processes; hardening phases; TMCP steel; weld; HAZ

\section{Introduction}

Welding processes are characterised by many features related to the variable field of temperatures and to widely changeable physical and mechanical properties of materials being welded. The character of the welded joint HAZ formation affected by a welding thermal cycle is responsible for the formation of structures characterised by significant diversity. The welding thermal cycle, i.e. changes of temperatures at points of a joint in time, includes changes of temperature caused by the flow of heat at every point of a given volume and effects resulting from such changes. Types of thermal cycles affecting a given weld metal and the HAZ affect structural and mechanical properties. The control of heat flow dynamics is a condition of successful welding. A momentary cooling rate is changeable and decreases along with decreasing temperature. Usually, a cooling time in the temperature range of 800 to $500^{\circ} \mathrm{C}\left(\mathrm{t}_{8 / 5}\right)$ is adopted as a parameter characterising cooling conditions. Therefore, types of structural transformations and the HAZ properties resulting from such transformations depend on the maximum temperature of a thermal cycle and on cooling time $t_{8 / 5}$. An increase in the maximum temperature rises an austenite overheating degree as well as increases an austenite grain growth and the amount of precipitates dissolved in austenite. The foregoing delays the transformation $\gamma-\alpha$ during cooling and moves the transformation towards lower temperatures. Recommendations concerning the welding of steels subjected to the TMCP found in reference publications are limited to filler metals, the reduction of hydrogen in welds by using low-hydrogen welding processes and to the restriction of pre-heating temperature which ought to be by 50 to $80^{\circ} \mathrm{C}$ lower than in the case of normalised and toughened steels and should not exceed $100^{\circ} \mathrm{C}$. The presence of vanadium, titanium and niobium in the base material has an advantageous effect on the formation of a fine-grained structure in the weld metal and in the HAZ (mainly due to fine precipitates of titanium nitrides, vanadium carbonitrides and of niobium, restricting the growth of austenite grains). Welding can disturb the processes mentioned above and lead to the uncontrolled precipitation of type MX phases. In addition, an excessively high nitrogen content in the base material combined with an overly low content of elements (aluminium and, particularly, titanium) bonding free nitrogen, may be responsible for the phenomenon of ageing responsible for the deteriorated weldability of steels [1-14].

\section{The range of studies}

The objective of individual research was to assess the effect of welding thermal process-induced precipitation processes taking place in $10 \mathrm{~mm}$ thick steel S700MC subjected to the

\footnotetext{
SILESIAN UNIVERSITY OF TECHNOLOGY, DEPARTMENT OF WELDING, 18A KONARSKIEGO STR., 44-100 GLIWICE, POLAND

\# Corresponding author: jacek.gorka@polsl.pl
} 
Thermo-Mechanical Control Process (TMCP) with accelerated cooling. Research-related analyses involved the base material, the HAZ and the weld area obtained using arc welding and laser beam welding without the use of filler metals. As regards steels subjected to the TMCP, particularly those having high yield points $(700 \mathrm{MPa})$, the obtainment of welds characterised by properties similar to the properties of the above named steels $\left(\mathrm{R}_{\mathrm{m}}, \mathrm{KV}\right)$ requires the use of filler metals having higher contents of alloying constituents than that present in the base material. However, such a requirement entails an increase in the carbon equivalent and may reduce weldability. The chemical composition of a weld and the value of the carbon equivalent result from the stirring of a material being welded with a filler metal. The analysis of chemical compositions of filler metals used when welding steel S700MC, performed using the Optical Emission Spectroscopy (OES) revealed the presence of alloying constituents increasing mechanical properties such as $\mathrm{Cr}$, Ni and $\mathrm{Mo}$, rising the carbon equivalent to a value above $0.6 \%$ (Table 1 ). This value is by twice higher than the carbon equivalent of the tested steel S700MC. Such a difference in the chemical composition of the filler metal and of the base material may lead to different properties of welded joints in the HAZ and in the weld area. The intensity of the aforesaid effect on mechanical and plastic properties of joints depends on the base material content in the weld, which in turn is affected by the linear energy of welding, a welding method and the chemical composition of a filler metal.

TABLE 1

Chemical compositions of filler metals used when welding steel S700MC, performed using the Optical Emission Spectroscopy (OES)

\begin{tabular}{|c|c|c|c|c|c|c|c|c|c|}
\hline \hline \multicolumn{7}{|c|}{ Chemical composition, weight concentration, \% } \\
\hline C & Si & Mn & $\mathbf{P}$ & $\mathbf{S}$ & $\mathbf{C r}$ & $\mathbf{M o}$ & $\mathbf{N i}$ & $\mathbf{N}^{*}$ & $\mathbf{C}_{\mathbf{e}}{ }^{* *}$ \\
\hline \multicolumn{7}{|c|}{ Solid wires for MAG welding; G Mn4Ni1,5CrMo } & \\
\hline 0,09 & 0,52 & 1,68 & 0,005 & 0,012 & 0,21 & 0,50 & 1,50 & 72 & 0,61 \\
\hline Cored wire for MAG welding; T Mn2NiCrMoMM1H5 & \\
\hline 0,09 & 0,37 & 1,36 & 0,015 & 0,010 & 0,43 & 0,39 & 2,23 & 86 & 0,63 \\
\hline \multicolumn{7}{|c|}{ Solid wires for TIG welding MT-NiMoCr } & \\
\hline 0,04 & 0,43 & 1,62 & 0,015 & 0,007 & 0,39 & 0,44 & 2,58 & 76 & 0,65 \\
\hline \multicolumn{7}{|c|}{ Solid wires for SAW welding S Mn3NiMo1 } & \\
\hline 0,07 & 0,43 & 1,97 & 0,026 & 0,006 & 0,59 & 0,39 & 2,25 & 84 & 0,75 \\
\hline$*$ & - The nitrogen was measured using the high temperature extraction \\
method, ppm & \\
$* * \mathrm{C}_{\mathrm{e}}$ & - carbon equivalent
\end{tabular}

\section{The results of studies}

\subsection{Base material analysis}

Research-related microscopic metallographic tests revealed that the tested steel, at the as-delivered state, was characterised by a bainitic-ferritic structure with visible plastic strain effects (Fig. 1). The OES-based analysis of the chemical composition of steel S700MC revealed that the content of carbon amounted to $0.056 \%$ by weight and that contents of hardening microagents, i.e. titanium, niobium and vanadium were $0.12 \%, 0.044 \%$ and
$0.006 \%$ respectively. The total content of the alloying microagents did not exceed a permissible concentration of $0.22 \%$. The content of nitrogen determined using the high-temperature extraction method amounted to approximately $70 \mathrm{ppm}$. Appropriate mechanical and plastic properties of the tested steel were obtained using the Thermo-Mechanical Control Process through precipitation, solid solution and strain hardening as well as grain refinement-related processes. Elements responsible for the hardening of steel S700MC were $\mathrm{Ti}$ and $\mathrm{Nb}$.

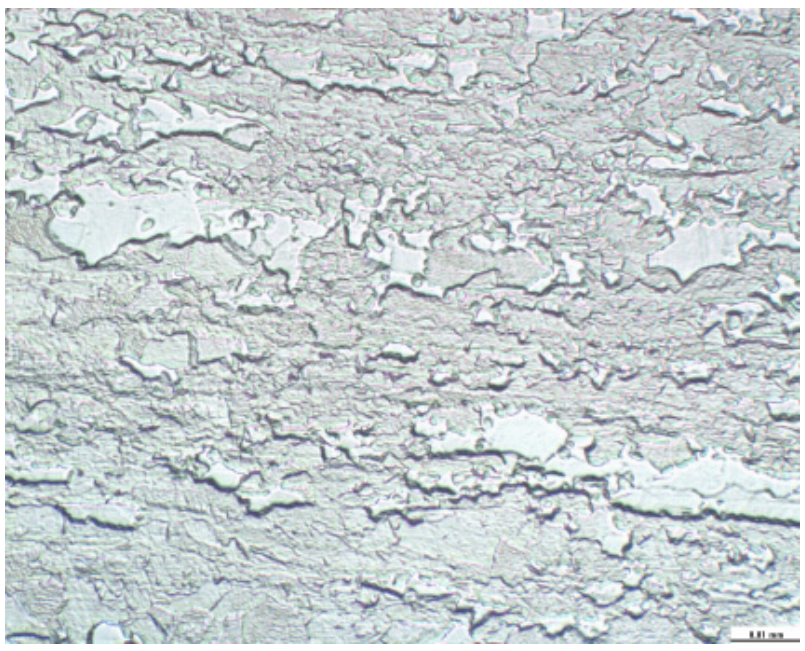

Fig. 1. Structure of bainitic-ferritic steel S700MC with visible effects of plastic deformation

The tests of thin foils performed using a transmission electron microscope revealed that the hardening of steel S700MC was primarily caused by $(\mathrm{Ti}, \mathrm{Nb})(\mathrm{C}, \mathrm{N})$ dispersive precipitates (being between several and less than twenty nanometres in size). The precipitation hardening was primarily affected by dispersive precipitates being several nanometres in size, precipitated in the steel in ferrite during cooling (Fig. 2). Particles being more than ten nanometres in size did not greatly contribute to precipitation hardening, yet they restricted the growth of re-crystallised austenite grains, thus favouring the formation of a fine-grained structure. The re-crystallised austenite grain growth in the tested steel was restricted by $(\mathrm{Nb}, \mathrm{Ti}) \mathrm{C}$ niobium-dominated carbide precipitates having globular shapes and diameters of approximately $10 \mathrm{~nm}$ (Fig. 2), (Ti,Nb)C carbide precipitates being approximately $20 \mathrm{~nm}$ in size (Fig. 3) and (Ti,Nb)(C,N) precipitates being approximately $50 \mathrm{~nm}$ in size. The dual morphology of some titanium and niobium carbonitride precipitates indicates that $\mathrm{NbC}$ carbides precipitated epitaxially at high temperature, forming complex type $(\mathrm{Ti}, \mathrm{Nb})(\mathrm{C}, \mathrm{N})$ precipitates on characteristic quadrangular TiN particles. In addition, tests involving light microscopy and the analysis of the surface distribution of chemical elements revealed that the base material contained significant precipitates of Ti carbonitrides and complex $(\mathrm{Ti}, \mathrm{Nb})$ carbonitrides being between several and less than twenty $\mu \mathrm{m}$ in size (Fig. 4,5).

These results demonstrate that the obtainment of appropriate mechanical properties during the thermomechanical processing 


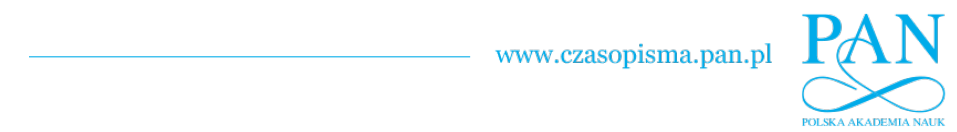

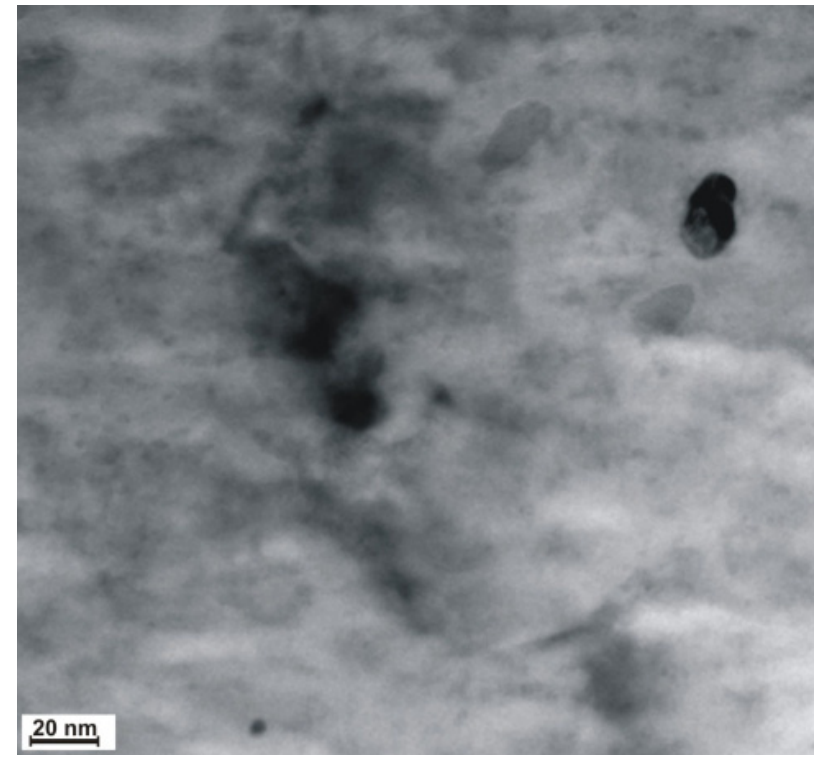

Fig. 2. View of precipitation of carbonitride $(\mathrm{Ti}, \mathrm{Nb})(\mathrm{C}, \mathrm{N})$ with a plurality of small precipitates of dispersion corresponding to the strengthening of steel

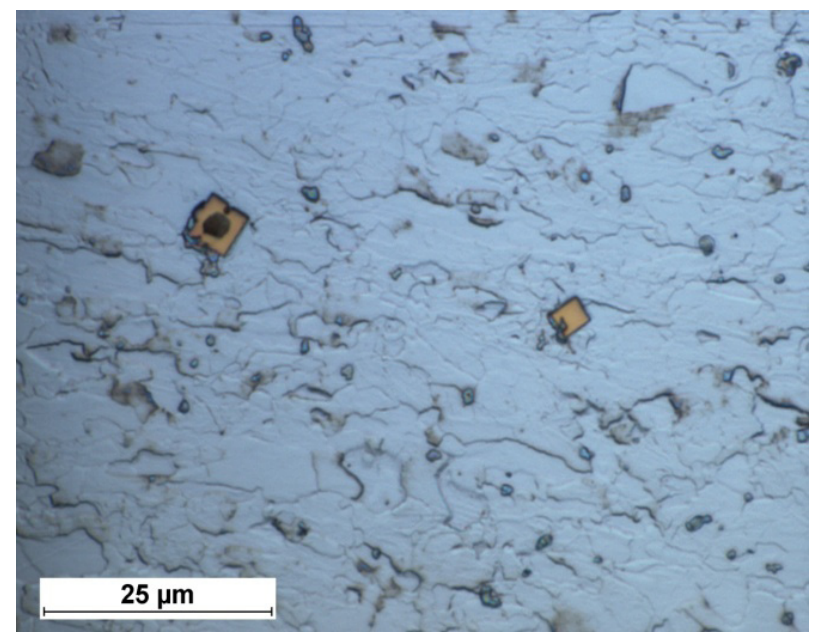

Fig. 4. View of precipitation of a crystallized on pollution

of steel S700MC does not require a large content of alloying micro-constituents, particularly titanium. The high activity of titanium in relation to nitrogen and carbon was responsible for the bonding of titanium in stable TiN precipitates, next TiC and type $(\mathrm{Ti}, \mathrm{Nb})(\mathrm{C}, \mathrm{N})$ complex precipitates. Taking into consideration atomic masses of chemical elements it was calculated that $\mathrm{Ti}$ and $\mathrm{Nb}$ bonded more than $0.02 \% \mathrm{C}$. As a result, the content of free carbon taking part in hardening through phase and structural transformations was low (approximately $0.03 \%$ ).

\subsection{HAZ analyses}

The HAZ areas of steel S700MC heated up to between 400 and $700^{\circ} \mathrm{C}$ were characterised by lower toughness than that of the base material at a temperature of $20^{\circ} \mathrm{C}$. A decrease in toughness in this temperature range should be ascribed to

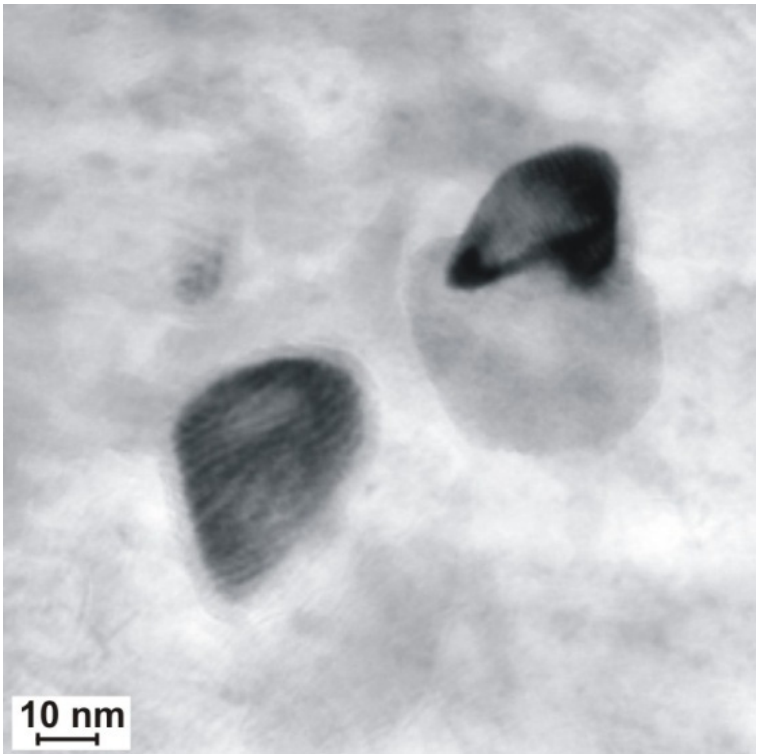

Fig. 3. Dispersive precipitation of carbides $(\mathrm{Ti}, \mathrm{Nb}) \mathrm{C}$ in $\mathrm{S} 700 \mathrm{MC}$ steel, limiting the growth of recrystallized austenite grains

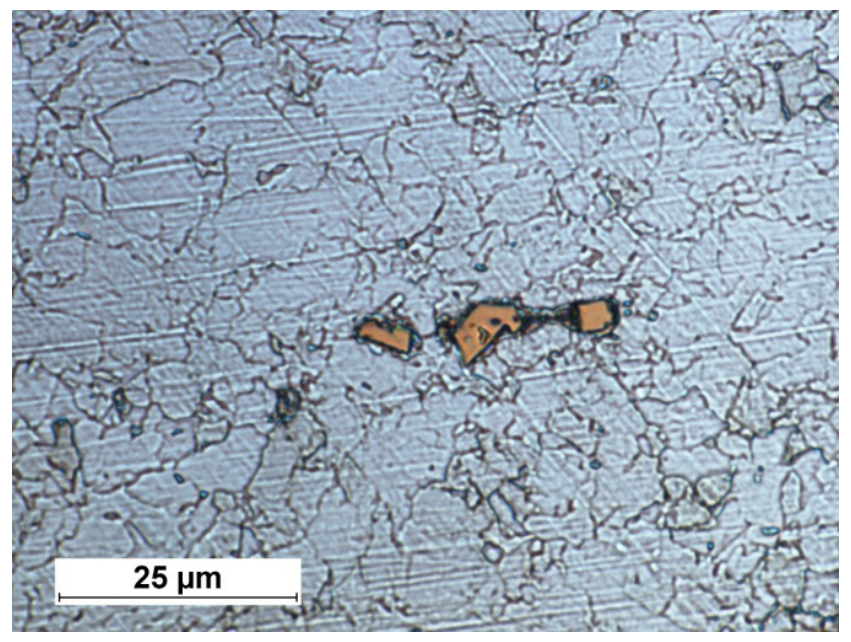

Fig. 5. View of a cluster of precipitates a characteristic sharp edges

ageing and blocked dislocation. In the temperature range of $800-900^{\circ} \mathrm{C}$, it was possible to observe a decrease in hardness and a sharp increase in toughness up to $300 \mathrm{~J} / \mathrm{cm}^{2}$, which could be attributed to the decay of precipitation hardening through the coagulation of precipitates, the passage of hardening constituents to the matrix and grain re-crystallisation processes. Microscopic examinations performed using an electron microscope did not reveal that the HAZ contained high-dispersive precipitates (of several $\mathrm{nm}$ in size) of hardening phases, responsible for precipitation hardening. Therefore, it can be assumed that the process of coagulation took place. The coagulation of $(\mathrm{Ti}, \mathrm{Nb})(\mathrm{C}, \mathrm{N})$ and (Ti,Nb)C precipitates (being $200 \mathrm{~nm}$ in size) was confirmed by microscopic examinations performed by means of an electron microscope (Fig. 6). The exceeding of $1000^{\circ} \mathrm{C}$ was followed by a sharp decrease in toughness to several $\mathrm{J} / \mathrm{cm}^{2}$. The decrease in toughness in the high-temperature part of the HAZ could be attributed to an increase in hardening phases dissolved in the 


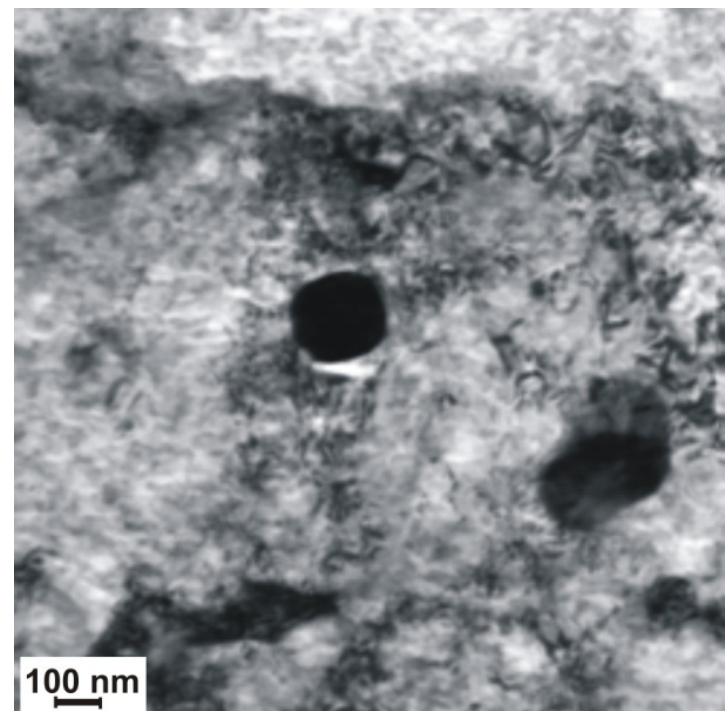

Fig. 6. Separating coagulated carbide precipitations $(\mathrm{Ti}, \mathrm{Nb})(\mathrm{C}, \mathrm{N})$ in the simulated $\mathrm{HAZ}$ heated to a temperature of $800^{\circ} \mathrm{C}$

matrix and their another uncontrolled precipitation in the form of numerous fine-dispersive precipitates (of several $\mathrm{nm}$ in size) in the matrix and greater $(\mathrm{Ti}, \mathrm{Nb})(\mathrm{C}, \mathrm{N})$ particles (of between 100 and $200 \mathrm{~nm}$ in size) (Fig. 7). Fine-dispersive precipitates hardened steel and significantly increased type 2 internal stresses, thus decreasing plastic properties.

\subsection{Analysis of welds}

The OES-based analysis of the chemical composition of welds of joints made using MAG welding with a solid wire electrode, MAG welding with a flux-cored electrode, TIG welding and submerged arc welding revealed that the chemical composition of the weld material was the result of the stirring of filler metal alloying constituents with the partially melted base material (Table 2).

TABLE 2

The chemical composition of the weld together with the calculated carbon equivalent

\begin{tabular}{|c|c|c|c|c|c|c|c|c|c|}
\hline \hline \multicolumn{7}{|c|}{ Chemical composition, weight concentration, \% } \\
\hline C & Mn & Si & S & P & Cr & Ni & Mo & $\mathbf{N}^{*}$ & $\mathbf{C}_{\mathbf{e}}{ }^{* *}$ \\
\hline \multicolumn{7}{|c|}{ MAG, solid wires, linear welding energy: $8 \mathrm{~kJ} / \mathrm{cm}$} \\
\hline 0,090 & 1,46 & 0,46 & 0,012 & 0,009 & 0,187 & 1,26 & 0,42 & 78 & 0,53 \\
\hline \multicolumn{7}{|c|}{ MAG, cored wire, linear welding energy: $7 \mathrm{~kJ} / \mathrm{cm}$} \\
\hline 0,081 & 1,52 & 0,57 & 0,013 & 0,009 & 0,168 & 1,16 & 0,43 & 93 & 0,53 \\
\hline \multicolumn{7}{|c|}{ TIG, solid wires, linear welding energy: $10 \mathrm{~kJ} / \mathrm{cm}$} \\
\hline 0,074 & 1,58 & 0,43 & 0,009 & 0,009 & 0,192 & 1,02 & 0,18 & 83 & 0,47 \\
\hline \multicolumn{7}{|c|}{ SAW, solid wires, linear welding energy: $20 \mathrm{~kJ} / \mathrm{cm}$} \\
\hline 0,073 & 1,51 & 0,30 & 0,004 & 0,017 & 0,541 & 1,88 & 0,45 & 78 & 0,50 \\
\hline \multicolumn{7}{|c|}{ Laser welding, linear welding energy: $5 \mathrm{~kJ} / \mathrm{cm}$} \\
\hline 0,040 & 1,61 & 0,137 & 0,005 & 0,009 & - & - & - & 72 & 0,31 \\
\hline$*$ & The nitrogen was measured using the high temperature extraction \\
method, ppm & carbon equivalent \\
$* \mathrm{C}_{\mathrm{e}}$ & -
\end{tabular}

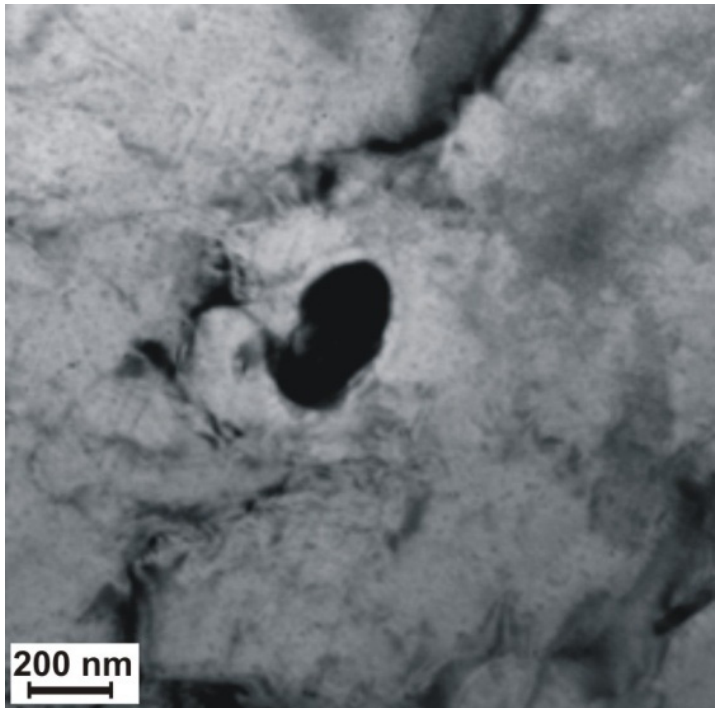

Fig. 7. Separation precipitation carbide $(\mathrm{Ti}, \mathrm{Nb}) \mathrm{C}$ along with numerous disperse precipitates of the same type in a simulated HAZ heated to a temperature of $1300^{\circ} \mathrm{C}$

During the welding of steel S700MC subjected to the TMCP, in each case of welding with a filler metal, the base material carbon equivalent was significantly lower than the carbon equivalent of the weld. Tests revealed that the weld area contained $\mathrm{Ni}$, Mo and $\mathrm{Cr}$, i.e. chemical elements ensuring the obtainment of appropriate mechanical and plastic properties of the weld. During laser beam welding, the chemical composition of the weld corresponded to the chemical composition of the base material (steel S700MC). During welding, an increase in the base material content in the weld was accompanied by increased contents of alloying microagents such as $\mathrm{Ti}$ and $\mathrm{Nb}$. The increase in these microagents was particularly visible near the fusion line, which was confirmed by a detailed chemical composition analysis performed using an electron microprobe X-ray analyser (Fig. 8).

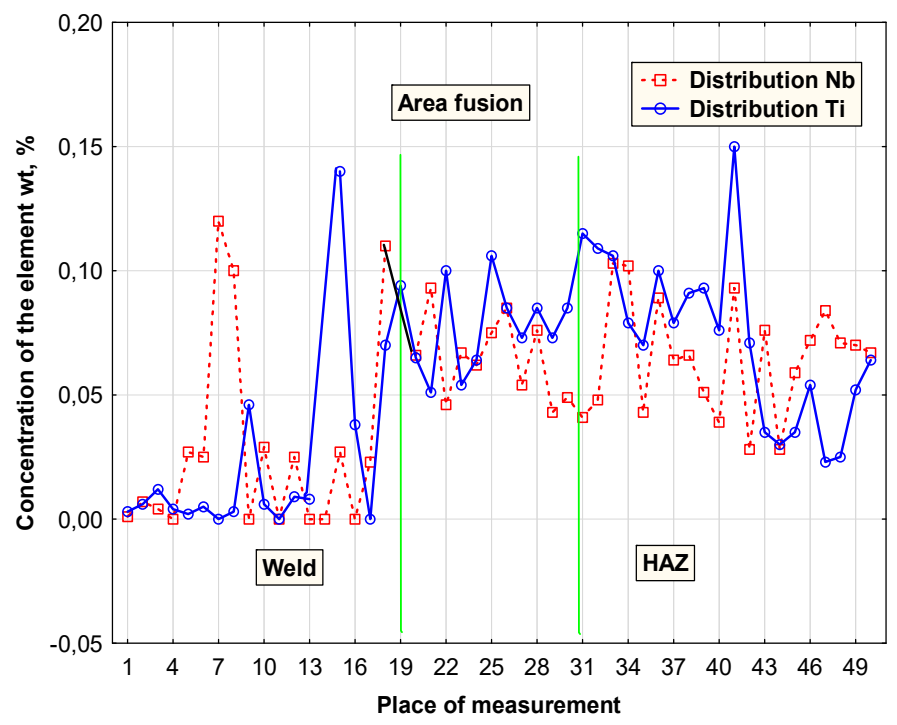

Fig. 8. Distribution of $\mathrm{Ti}$ and $\mathrm{Nb}$ in the field of fusion welded joint using MAG method and S700MC steel solid wire with linear energy of $8 \mathrm{~kJ} / \mathrm{cm}$ 
Microscopic examinations revealed that, during arc welding, carbonitride precipitates of several $\mu \mathrm{m}$ in size and present in the weld area dissolved entirely, which, in cases of longer crystallisation times (higher welding linear energies) could lead to significant precipitation hardening and weld toughness reduction. The cooling was characterised by the lack of proper conditions for another controlled precipitation of fine-dispersive carbides and $(\mathrm{Ti}, \mathrm{Nb})$ carbonitrides in the weld. Tests performed utilising a transmission electron microscope and involving the area of the welds made using low linear energy revealed the decay of a precipitation hardening effect (the lack of precipitates being several $\mathrm{nm}$ in size) and the presence of coagulated titanium-niobium precipitates (of $100 \mathrm{~nm}$ in size) (Fig. 9a-c), restricting the growth of re-crystallised austenite grains, thus improving plastic properties.

In addition, the areas of the welds made using low linear energy revealed the presence of spherical stable $\mathrm{TiO}$ precipitates being $200 \mathrm{~nm}$ in size and intensively triggering the nucleation of acicular ferrite inside austenite grains (Fig. 10). Acicular ferrite is responsible for high mechanical and plastic properties of welds. An increase in welding linear energy was accompanied by an increase in the content of hardening phases dissolved in the matrix and, during cooling, by their another uncontrolled precipitation in the form of numerous fine-dispersive $(\mathrm{Ti}, \mathrm{Nb})$ $(\mathrm{C}, \mathrm{N})$ precipitates (of several $\mathrm{nm}$ in size) leading to a dislocation density increase triggered by type 2 internal stresses. During laser beam welding, in spite of low welding linear energy, toughness was very low (below $20 \mathrm{~J} / \mathrm{cm}^{2}$ ). In the welds made using laser welding without a filler metal, the content of $\mathrm{Ti}$ and $\mathrm{Nb}$ was significantly higher than that in the welds made utilising arc welding (the filler metal did not contain $\mathrm{Ti}$ or $\mathrm{Nb}$ ). A significant content of hardening phases in the weld during cooling led to intense precipitation hardening through fine-dispersive $(\mathrm{Ti}, \mathrm{Nb})(\mathrm{C}, \mathrm{N})$ type precipitates of several $\mathrm{nm}$ in size, precipitated near greater $(\mathrm{Ti}, \mathrm{Nb}) \mathrm{N}$ and $\mathrm{TiC}$ particles being $100 \mathrm{~nm}$ in size (Fig. 11). This increased dislocation density and reduced plastic properties. In high-power welding conditions, in $\mathrm{TiO}$ precipitates, acicular ferrite formed inside austenite grains may transform into lower acicular ferrite of significantly inferior plastic properties.

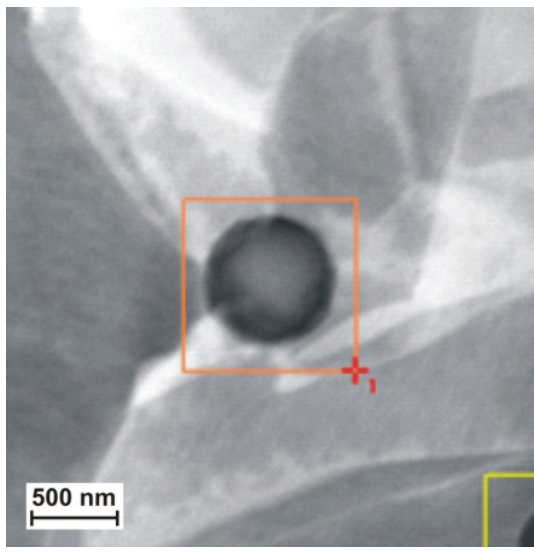

a) View of precipitation

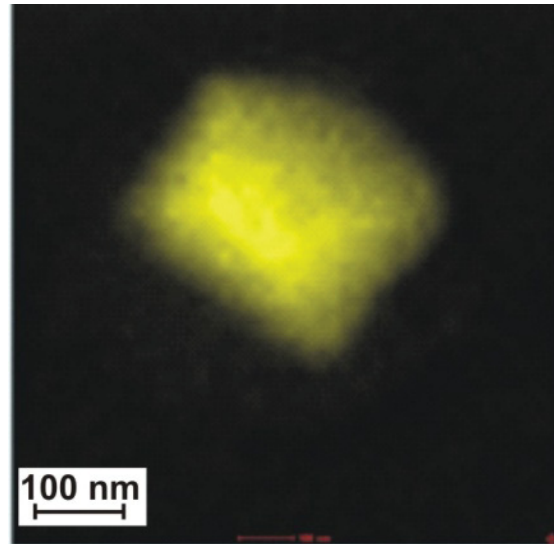

b) Surface distribution of titanium

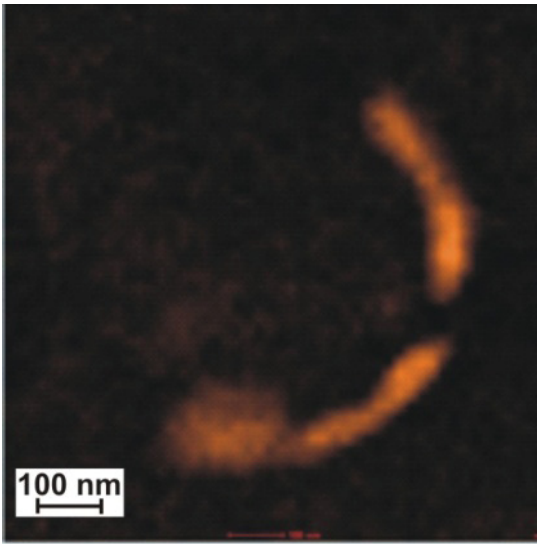

c) Surface distribution of niobium

Fig. 9. Precipitation of titanium-niobium in steel weld S700MC made using MAG method, with flux-cored wire and linear energy $15 \mathrm{~kJ} / \mathrm{cm}$

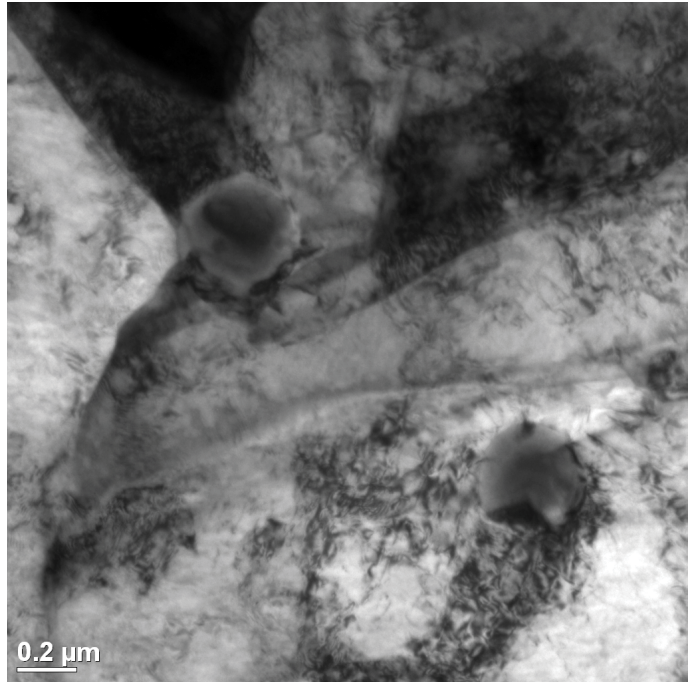

Fig. 10. Spherical TiO precipitation in the weld steel S700MC made using MAG method and solid wire with linear energy of $8 \mathrm{~kJ} / \mathrm{cm}$

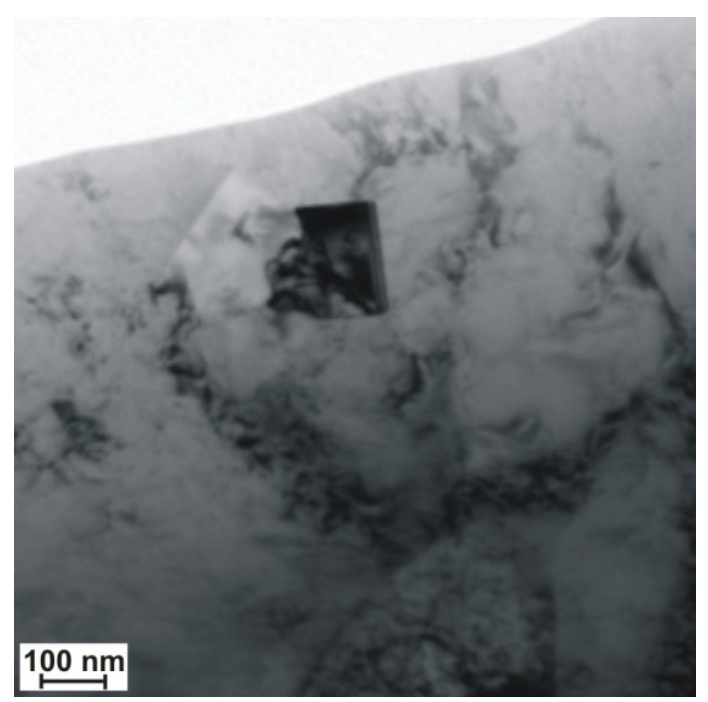

Fig. 11. Precipitation of TiC carbide along with numerous dislocations in the S700MC steel weld, welded laser beam and linear energy of 5 


\section{Conclusions}

The analysis of the base material of steel S700MC revealed that the steel was characterised by a strongly defective bainiticferritic structure. The chemical composition of the steel, the presence of titanium and niobium microagents as well as the control of a strain degree, rolling temperature and a post-roll cooling rate enabled the obtainment of a yield point amounting to $700 \mathrm{MPa}$. A very low content of carbon $(0.056 \%$ by weight $)$, largely bonded by $\mathrm{Ti}$ and $\mathrm{Nb}$, translated into the low carbon content in the hardening through the supersaturation of solution $\alpha$ and reduced the carbon content effect during transformations $\gamma-\alpha$. Tests performed using a transmission electron microscope revealed that the hardening of steel S700MC was primarily caused by dispersive $(\mathrm{Ti}, \mathrm{Nb})(\mathrm{C}, \mathrm{N})$ precipitates (being between several and less than twenty nanometres in size). The precipitation hardening was primarily affected by dispersive precipitates being several nanometres in size, blocking dislocation movements and precipitating in the steel in ferrite during cooling. Greater particles (of more than ten nanometres in size) did not greatly contribute to precipitation hardening, yet they restricted the growth of re-crystallised austenite grains, thus favouring the formation of a fine-grained structure. The HAZ areas heated up to between 400 and $700^{\circ} \mathrm{C}$ were characterised by a decrease in toughness due to ageing and blocked dislocation. In the range of $800-900^{\circ} \mathrm{C}$ it was possible to observe a decrease in hardness and a sharp increase in toughness, which could be ascribed to the decay of precipitation hardening through the coagulation of precipitates, the passage of hardening constituents to the matrix and grain re-crystallisation processes. The exceeding of $1000^{\circ} \mathrm{C}$ was followed by a sharp decrease in toughness to several $\mathrm{J} / \mathrm{cm}^{2}$. The decrease in toughness in the high-temperature part of the HAZ could be ascribed to an increase in hardening phases dissolved in the matrix and their another uncontrolled precipitation in the form of numerous fine-dispersive precipitates (of several $\mathrm{nm}$ in size) in the matrix and greater type $(\mathrm{Ti}, \mathrm{Nb})(\mathrm{C}, \mathrm{N})$ particles (of between 100 and $200 \mathrm{~nm}$ in size). During welding, an increase in the base material content in the weld was accompanied by increased contents of $\mathrm{Ti}$ and $\mathrm{Nb}$ alloying microagents, particularly near the fusion line. A large amount of precipitates of hardening chemical elements had a very negative influence on plastic properties of welds. The longer the time when the base material remained in the liquid state, the greater the amount of microagents could dissolve in the matrix. During cooling, such microagents could precipitate again or remain in the solution. High temperatures of the liquid metal pool dissolved even the most stable TiN particles. The cooling was characterised by the lack of proper conditions for another controlled precipitation of fine-dispersive carbides and $(\mathrm{Ti}, \mathrm{Nb})$ carbonitrides responsible for precipitation hardening.

\section{Acknowledgments}

This work was funded through the following research grant: „Control properties and structure of steel joints for thermomechanically processed high yield", nr N N507 321040 , Silesian University of Technology in Gliwice.

\section{REFERENCES}

[1] K. Nishioka, K. Ichikawa, Progress in termomechanical control of steel plates and their commercialization, Science and Technology of Advanced Materials 13 (2), 1-20 (2012).

[2] A. Lisiecki, Titanium Matrix Composite Ti/TiN Produced by Diode Laser Gas Nitriding, Metals 5(1), 54-69 (2015), doi:10.3390/ met5010054.

[3] A. Grajcar, K. Radwański., H. Krztoń, Microstructural analysis of a thermomechanically processed Si-Al TRIP steel characterized by EBSD and X-ray techniques, Solid State Phenomena 203-204, 34-37 (2013).

[4] A. Lisiecki, Welding of thermomechanically rolled fine-grain steel by different types of lasers, Archives of Metallurgy and Materials 59 (4), 1625-163 (2014).

[5] M. Opiela, Thermomechanical treatment of Ti-Nb-V-B microalloyed steel forgings, Materiali in Technologije 4, 587-591 (2014).

[6] T. Gladman, The physical metallurgy of microalloyed steels, The Institute of Materials, Cambridge University Press, Cambridge 1997.

[7] M. Opiela, Effect of thermomechanical processing of the microstructure and mechanical properties of Nb-Ti-V microalloyed steel, Journal of Materials Engineering and Performance 9, 3379-3388 (2014).

[8] J. Górka, Analysis of simulated welding thermal cycles S700MC using a thermal imaging camera, Advanced Material Research ISI Proceedings 837, 375-380 (2014).

[9] A. Grajcar, M. Różański, S. Stano, A. Kowalski, Microstructure characterization of laser-welded $\mathrm{Nb}$-microalloyed silicon-aluminum TRIP steel, Journal of Materials Engineering and Performance 23 (9), 3400-3406 (2014).

[10] M. Żuk, J. Górka, A. Czupryński, M. Adamiak, Properties and structure of the weld joints of quench and tempered $4330 \mathrm{~V}$ steel, Metalurgija 55 (4), 613-616 (2016).

[11] D. Janicki, Disk laser welding of armor steel, Archives of Metallurgy and Materials 59 (4), 1641-1646 (2014).

[12] J. Górka, Microstructure and properties of the high-temperature (HAZ) of thermo-mechanically treated S700MC high-yield-strength steel, Materiali in tehnologije 50 (4), 617-621 (2016).

[13] K.S. Bang, W.Y. Kim, Estimation and prediction of HAZ softening in thermomechanically controlled - rolled and accelerated - cooled steel. Welding Journal 81, 174-179 (2002).

[14] J. Górka, Study of structural changes in S700MC steel thermomechanically treated under the influence of simulated welding thermal cycles, Indian Journal of Engineering and Materials Sciences 22, 497-502 (2015). 